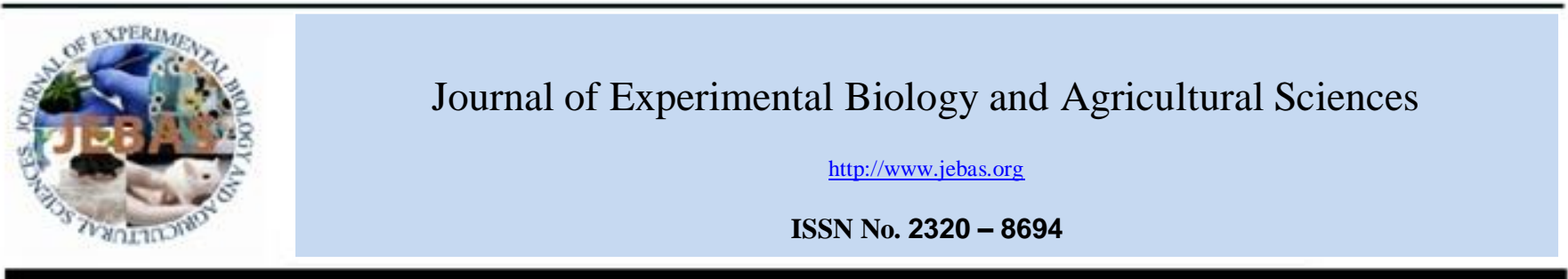

\title{
PARAMETERS OF AMMI MODEL TO ASSESS G×E INTERACTION OF MALT BARLEY GENOTYPES
}

\author{
Ajay Verma ${ }^{1 *}$, V Kumar, AS Kharab, GP Singh \\ ${ }^{1}$ ICAR-Indian Institute of Wheat \& Barley Research, Karnal 132001 Haryana
}

Received - April 16, 2019; Revision - May 20, 2019; Accepted - June 07, 2019

Available Online - June 10, 2019

DOI: http://dx.doi.org/10.18006/2019.7(3).273.280

KEYWORDS
G×E interactions
AMMI model
ASV
ASTAB
EV
MASV

\begin{abstract}
AMMI analysis of twenty three promising malt barley genotypes were evaluated at nine major locations of the country to interpret complex genotype by environment (GE) interactions. Combined analysis of variance indicated the larger and highly significant $G \times E$ interaction. Seven significant IPCA's were used to calculate AMMI based measures. Type 1 measures (EV1, ASTAB1, D1), considered G12, G8, G19, G20 as desirable genotypes and G9, G2 as of unstable performance; while type 2 (EV2, ASTAB2, D2 and ASV) considered G12, G10, G22, G15 as genotypes of choice and G9, G2 as unsuitable; type 3 (EV3, ASTAB3 and D3) pointed towards G22, G12, G23, G3 as of stable type along with G2, G9 of unstable type; type 5 measures (EV5, ASTAB5, SIPC5 and D5) selected G22, G12, G23, G3 genotypes and G2 \& G9; type 7 utilized more than 97\% of G×E interaction (EV7, ASTAB7, MASV and D7) identified G22, G3, G12, G6 as genotypes of recommendations and G2 \& G9 were detected as the unstable genotypes. AMMI based measures recommended genotypes G12, G13, G22 and G3 had the moderate yield performance while G19 was of high yield. Association analysis among measures by multivariate hierarchical Ward's clustering approach grouped into three major clusters. Largest group clubbed as many as 16 measures while yield combined with IPCA2, and SIPC1, SIPC2, SIPC3, SIPC5, SIPC7 in second group.
\end{abstract}

* Corresponding author

E-mail: ajay.verma1 @icar.gov.in (Ajay Verma)

Peer review under responsibility of Journal of Experimental Biology and Agricultural Sciences.

Production and Hosting by Horizon Publisher India [HPI] (http://www.horizonpublisherindia.in/).

All rights reserved.
All the articles published by Journal of Experimental Biology and Agricultural Sciences are licensed under a Creative Commons Attribution-NonCommercial 4.0 International License Based on a work at www.jebas.org.

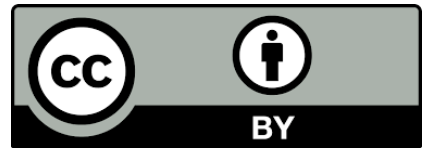




\section{Introduction}

Barley is cultivated worldwide mainly for malt and beer production (Kilic, 2014). GXE interaction governs the identification of the stable yield performer genotypes suitable for a specific environment or for several environments (Akbarpour et al., 2014). An efficient assessment of $\mathrm{G} \times \mathrm{E}$ interaction is very essential to determine the yield potential of genotypes along with stable yield performance (Dehghani et al., 2010). ANOVA analysis is useful to test the significance of interaction but this test fails to partition into total variation into simple and cross over interactions (Flores et al., 1998). Partitioning and interpretation of $\mathrm{G} \times \mathrm{E}$ interaction is carried out by linear regression still this technique have inherent deficiencies for confounding of main effects (Tekdal \& Kendal, 2018) as well as failure to account for non linear genotypic response (Yau, 1995). Other multiplicative model analysis based on principal component lacked to describe the additive main effects (Sabaghnia et al., 2013; Bocianowski et al., 2019a).
AMMI model (Additive main effects and multiplicative interaction model) observed as choice of researchers with emphasis on main effects and interactions both (Crossa et al., 1990; Mohammadi et al., 2015; Nowosad et al., 2018). Multi Environment trials of all crops pay same attention to efficient estimation of main and interaction effects (Kendal \& Tekdal, 2016). Prime objectives of this study are application of different AMMI based measures and explore the association analysis among different measures in identifying adapted genotypes.

\section{Materials and Methods}

Twenty three promising malt barley genotypes were evaluated at nine major locations of the country during cropping season of 2017-2018 in field trials via randomized complete block design with four replications. Fields were prepared nicely and agronomic recommendations were followed to harvest good crop. Parentage details and environmental conditions had mentioned in table 1 for

Table 1 Parentage details of malt barley genotypes along with environmental conditions

\begin{tabular}{|c|c|c|c|c|c|c|c|}
\hline Code & Genotype & Parentage & Code & Environments & Latitude & Longitude & Mean sea level \\
\hline G 1 & DWRB181 & DWRUB52/DWRB77 & E 1 & Bawal & $28^{\circ} 10^{\prime} \mathrm{N}$ & $76^{\circ} 59^{\prime} \mathrm{E}$ & 263 \\
\hline G 2 & RD2986 & DWR39/RD-2651 & E 2 & Durgapura & $26^{\circ} 51 \mathrm{~N}$ & $75^{\circ} 47^{\prime} \mathrm{E}$ & 390 \\
\hline G 3 & KB1638 & K551/NDB1295 & E 3 & Hisar & $29^{\circ} 10^{\prime} \mathrm{N}$ & $75^{\circ} 46^{\prime} \mathrm{E}$ & 215.2 \\
\hline G 4 & DWRB183 & DWR28/DWRUB52 & E 4 & SG Nagar & $29^{\circ} 90^{\prime} \mathrm{N}$ & $73^{\circ} 87^{\prime} \mathrm{E}$ & 176 \\
\hline G 5 & DWRB182 & DWRUB52/DWRB78 & E 5 & Ludhiana & $30^{\circ} 54^{\prime} \mathrm{N}$ & $75^{\circ} 52^{\prime} \mathrm{E}$ & 247 \\
\hline G 6 & RD2988 & DWRUB52/RD-2651 & E 6 & Bathinda & $30^{\circ} 21^{\prime} \mathrm{N}$ & $74^{\circ} 95^{\prime} \mathrm{E}$ & 208 \\
\hline G 7 & DWBR137 & DWR28/DWRUB64 & E 7 & Mathura & $27^{\circ} 49^{\prime} \mathrm{N}$ & $77^{\circ} 67^{\prime} \mathrm{E}$ & 187 \\
\hline G 8 & DWRB160* & DWRB62/DWRB73 & E 8 & Pantnagar & $29^{\circ} 02^{\prime} \mathrm{N}$ & $79^{\circ} 48^{\prime} \mathrm{E}$ & 237 \\
\hline G 9 & DWRB184 & DWRUB52/DWR81 & E 9 & Karnal & $29^{\circ} 43^{\prime} \mathrm{N}$ & $76^{\circ} 58^{\prime} \mathrm{E}$ & 252 \\
\hline G 10 & Andreia & & & & & & \\
\hline G 11 & PL904 & DWRUB64/RD2668 & & & & & \\
\hline G 12 & RD2849 (c) & DWRUB52/PL705 & & & & & \\
\hline G 13 & DWRB101 (c) & DWR28/BH581 & & & & & \\
\hline G 14 & Explorer & & & & & & \\
\hline G 15 & DWRB123 (c) & DWRUB54/DWR51 & & & & & \\
\hline G 16 & RD2985 & Clipper/RD-2668//DWR73 & & & & & \\
\hline G 17 & BH902 (c) & BH495/RD2552 & & & & & \\
\hline G 18 & KB1634 & Lakhan/JB137 & & & & & \\
\hline G 19 & DWRB187 & RD2035/ RD2552 & & & & & \\
\hline G 20 & ABI Voyager & & & & & & \\
\hline G 21 & Danielle & & & & & & \\
\hline G 22 & PL905 & VJM 604/PL764 & & & & & \\
\hline G 23 & RD2987 & Clipper/EB921//RD-2668 & & & & & \\
\hline
\end{tabular}


ready reference. More over grain yield was analyzed further to estimate the G×E interaction component by AMMI analysis. The description of widely used measures based on AMMI analysis was mentioned for completeness.

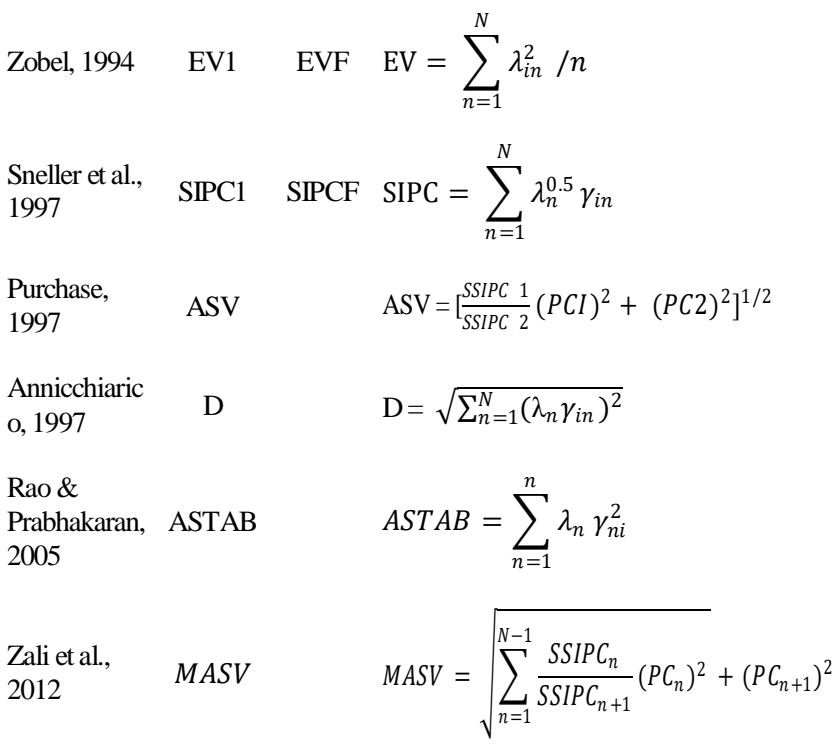

$\mathrm{EV} 1=\mathrm{EV}$ for first IPCA; EVF $=\mathrm{EV}$ for seven IPCA \& SIPC1 $=$ SIPC for first IPCA, SIPC $2=$ SIPC for first two IPCAs

AMMI model computations were performed by software MATMODEL version 3.0 (Gauch, 2007) and SAS software version 9.3.

\section{Results and Discussion}

The combined analysis of variance (ANOVA) showed highly significant differences between the genotypes (G), which supported the considerable variability with respect to grain yield in this study (Table 2). Significant differences were also observed among the environments (E). AMMI analysis of variance showed that environments, genotypes and $\mathrm{G} \times \mathrm{E}$ interaction effects accounted for $58 \%, 12 \%$ and $22.5 \%$ of the total variation, respectively. Variance explained by the $\mathrm{G} \times \mathrm{E}$ interaction effect was nearly two times that of genotype effects. This was further divided into seven significant interaction principal component axes (IPCAs). First four IPCA's contributed more than $80 \%$. IPCA1 explained $31.1 \%$ of the variation affected by interaction, while IPCA2, IPCA3 and IPCA4 accounted for 22.7, 16.7 and $10.6 \%$, respectively. Since the main effect of genotypes on grain yield was highly significant, mean yield was considered as the first parameter for assessing the yield potential of genotypes. In this respect, G7, G9, G19, G17 and G5 had the highest and genotypes G21, G14 and G10 had the lowest average yields across 09 environments.

Large magnitude of $\mathrm{G} \times \mathrm{E}$ interactions for yield found in this investigation are similar to those found in other crops (Sabaghnia et al., 2012; Mortazavian et al., 2014). The high significance of GE interactions is indicating the studied genotypes exhibited both crossover and non-crossover types of GE interaction. Total $\mathrm{G} \times \mathrm{E}$ (35116.26) was partitioned into $\mathrm{G} \times \mathrm{E}$ noise (3073.76) that is

Table 2 AMMI analysis of malt barley genotypes

\begin{tabular}{|c|c|c|c|c|c|c|}
\hline Source & df & MS & Level of significance & $\%$ of Total SS & $\%$ of GxE SS & Cumulative $\%$ SS by PCA's \\
\hline Treatments & 206 & 704.6512 & $* * *$ & 93.05 & & \\
\hline Genotypes & 22 & 888.6938 & $* * *$ & 12.53 & & \\
\hline Environments & 8 & 11311.33 & $* * *$ & 58.01 & & \\
\hline GxE & 176 & 199.5242 & $* * *$ & 22.51 & & \\
\hline IPC1 & 29 & 376.2301 & $* * *$ & & 31.07 & 31.07 \\
\hline IPC2 & 27 & 294.8774 & $* * *$ & & 22.67 & 53.74 \\
\hline IPC3 & 25 & 234.49 & $* * *$ & & 16.69 & 70.44 \\
\hline IPC4 & 23 & 161.5521 & $* * *$ & & 10.58 & 81.02 \\
\hline IPC5 & 21 & 135.5105 & $* * *$ & & 8.10 & 89.12 \\
\hline IPC6 & 19 & 89.42937 & $* * *$ & & 4.84 & 93.96 \\
\hline IPC7 & 17 & 82.85984 & $* * *$ & & 4.01 & 97.97 \\
\hline Residual & 15 & 47.4968 & $* * *$ & & & \\
\hline Error & 621 & 17.46457 & & & & \\
\hline Total & 827 & 188.638 & & & & \\
\hline
\end{tabular}

Journal of Experimental Biology and Agricultural Sciences http://www.jebas.org 
$8.75 \%$ and $\mathrm{G} \times \mathrm{E}$ signal (32042.49) of $91.25 \%$. AMMI derived measures based on the use of significant IPCA's were calculated as EV1, ASTAB1, SIPC1, D1 measures (only first significant IPCA), while ASV, EV2, ASTAB2, SIPC2, D2 considered IPCA1 \& IPCA2 both, measures EV3, ASTAB3, SIPC3 and D3 used three IPCAs, EV5, ASTAB5, SIPC5 \& D5 (based on five IPCAs), whereas measures EV7, ASTAB7, SIPC7 and D7 utilized all significant IPCAs.

Explained variation of $\mathrm{G} \times \mathrm{E}$ interaction accounted by each of IPCA exploited by defined measures, as type-1 measures benefited $31.07 \%$, type- 2 measures utilized $53.74 \%$, type 3 measures used up to $70.44 \%$, type 5 measures benefited up to $89.1 \%$, while type 7 measures accounted for most of variation and utilized to the extent of benefits $97.9 \%$ (Table 2). This justifies the use of AMMI derived parameters based on the larger numbers of IPCAs results in the most usage of $\mathrm{G} \times \mathrm{E}$ interaction variations.

Minimum and maximum values of EV1 observed for G12, G8, G20, G19 and G9, G2 while corresponding to D1 were G12, G8, G20, G19 and G9, G2 absolute values of ASTAB1 for G12, G8, G20, G19 and G9, G2 and for SIPC1 were G17, G14, G21, G6 \& G9, G2, genotypes G7, G9, G19, G17 were of high yield and G21, G14 of low yield performance (Tables 3 \& 4).

Genotypes EV2 pointed towards G12, G10, G22 \& G15 as desirable at the same time undesirable genotypes (G9, G2), for values of D2 genotypes were G12, G10, G22, G15 \& G9, G2, whereas as per criterion of SIPC2 were G6, G14, G19, G16) \& G9, G4 and of ASTAB2 were G12, G10, G22, G15 \& G9, G2

Table 3 Principal components analysis of malt barley genotypes

\begin{tabular}{|c|c|c|c|c|c|c|c|c|c|c|c|}
\hline & & Yield & IPCA 1 & IPCA 2 & IPCA 3 & IPCA 4 & IPCA 5 & IPCA 6 & IPCA 7 & ASV & MASV \\
\hline G 1 & DWRB181 & 47.94 & 1.2854 & 0.8653 & -0.5628 & -0.3128 & 1.5982 & -0.1224 & 0.2926 & 1.74 & 3.47 \\
\hline G 2 & RD2986 & 47.36 & 3.0039 & -1.4643 & 2.5807 & 0.9765 & -0.7550 & -0.5527 & -0.7724 & 3.81 & 6.29 \\
\hline G 3 & KB1638 & 48.44 & -1.4427 & 0.3568 & 0.4008 & -0.7619 & 0.8400 & 0.7669 & 1.0419 & 1.73 & 3.03 \\
\hline G 4 & DWRB183 & 49.89 & 1.1253 & 1.9575 & -0.0542 & -0.1159 & 0.5759 & 0.6493 & -0.7277 & 2.36 & 3.63 \\
\hline G 5 & DWRB182 & 52.39 & 1.8720 & -0.0352 & -2.8564 & 0.1709 & 0.6254 & 1.4882 & -0.6779 & 2.19 & 5.68 \\
\hline G 6 & RD2988 & 42.33 & -1.7043 & -1.7110 & -1.0213 & 1.7796 & -1.7807 & 0.8318 & 0.3624 & 2.63 & 5.57 \\
\hline G 7 & DWBR137 & 58.86 & -0.7372 & 2.0129 & -0.7513 & -1.2641 & -0.3383 & -2.1201 & 0.9557 & 2.19 & 5.16 \\
\hline G 8 & DWRB160* & 52.17 & -0.2517 & 2.1653 & -1.6704 & 0.2797 & -1.8901 & -0.9560 & -0.5142 & 2.19 & 5.51 \\
\hline G 9 & DWRB184 & 55.89 & 3.6077 & 0.2804 & -0.4140 & 0.0493 & -1.1730 & -0.9440 & 0.0440 & 4.23 & 4.91 \\
\hline G 10 & Andreia & 42.06 & 0.8325 & -0.4839 & 1.5361 & -3.0298 & -0.1470 & 0.5405 & -0.2680 & 1.09 & 5.43 \\
\hline G 11 & PL904 & 45.64 & 1.1752 & 1.8465 & 1.6417 & 0.7087 & -0.5830 & 1.2382 & 0.8821 & 2.30 & 4.81 \\
\hline G 12 & RD2849 (c) & 49.61 & 0.0146 & 0.5695 & 0.3343 & 0.9487 & 0.9424 & 0.6381 & -2.0675 & 0.57 & 3.27 \\
\hline G 13 & DWRB101 (c) & 51.64 & -1.1996 & -0.6031 & 0.5299 & 1.1783 & 1.9515 & -0.4832 & -0.3605 & 1.53 & 4.19 \\
\hline G 14 & Explorer & 41.22 & -1.8659 & -1.1477 & -0.3131 & -1.0421 & 0.2506 & -0.3066 & -1.5544 & 2.47 & 3.66 \\
\hline G 15 & DWRB123 (c) & 50.14 & -0.6921 & -0.9681 & 1.2982 & 0.0220 & 1.6458 & -1.3177 & 0.1152 & 1.26 & 4.28 \\
\hline G 16 & RD2985 & 47.47 & -1.1497 & -0.8806 & 0.9640 & 1.7789 & -1.2227 & -1.3075 & -0.1385 & 1.61 & 4.60 \\
\hline G 17 & BH902 (c) & 54.17 & -1.9871 & 2.1003 & 0.2214 & 0.8491 & 0.2077 & 0.3033 & -0.6879 & 3.13 & 4.29 \\
\hline G 18 & KB1634 & 53.83 & -0.6737 & 1.1680 & 1.7332 & 0.7157 & 0.3759 & 0.5201 & 1.6729 & 1.41 & 4.07 \\
\hline G 19 & DWRB187 & 55.14 & 0.5322 & -1.3341 & -2.5779 & 0.8436 & 1.2020 & -0.7114 & 0.9174 & 1.47 & 5.40 \\
\hline G 20 & ABI Voyager & 43.25 & 0.3041 & -3.0918 & -0.2031 & -1.0428 & -0.2507 & 0.0654 & 0.1875 & 3.11 & 5.05 \\
\hline G 21 & Danielle & 40.83 & -1.8094 & 0.1373 & -0.0162 & -2.0856 & -1.3070 & 0.0342 & -0.7561 & 2.12 & 4.44 \\
\hline G 22 & PL905 & 49.08 & 0.6852 & -0.8120 & -0.7115 & -0.5930 & 0.2742 & -0.0411 & 1.3160 & 1.14 & 2.50 \\
\hline G 23 & RD2987 & 45.97 & -0.9247 & -0.9280 & -0.0882 & -0.0529 & -1.0421 & 1.7867 & 0.7368 & 1.43 & 3.70 \\
\hline
\end{tabular}

IPCA, principal component of interaction, ASV = AMMI stability value, MASV = Modified AMMI Stability value 
Table 4 AMMI based estimates of malt barley genotypes

\begin{tabular}{|c|c|c|c|c|c|c|c|c|c|c|}
\hline & EV1 & EV2 & EV3 & EV5 & EV7 & D1 & $\mathrm{D} 2$ & D3 & D5 & D7 \\
\hline DWRB181 & 0.0158 & 0.0121 & 0.0094 & 0.0156 & 0.0115 & 13.14 & 15.47 & 16.24 & 20.14 & 20.17 \\
\hline RD2986 & 0.0864 & 0.0552 & 0.0658 & 0.0447 & 0.0353 & 30.70 & 33.67 & 40.54 & 41.62 & 41.82 \\
\hline KB1638 & 0.0199 & 0.0107 & 0.0078 & 0.0092 & 0.0128 & 14.74 & 15.13 & 15.53 & 17.72 & 18.57 \\
\hline DWRB183 & 0.0121 & 0.0275 & 0.0184 & 0.0123 & 0.0123 & 11.50 & 21.78 & 21.79 & 22.21 & 22.67 \\
\hline DWRB182 & 0.0336 & 0.0168 & 0.0467 & 0.0296 & 0.0306 & 19.13 & 19.14 & 31.48 & 31.83 & 33.28 \\
\hline RD2988 & 0.0278 & 0.0303 & 0.0247 & 0.0371 & 0.0294 & 17.42 & 23.77 & 25.39 & 31.73 & 32.19 \\
\hline DWBR137 & 0.0052 & 0.0253 & 0.0193 & 0.0173 & 0.0314 & 7.53 & 20.46 & 21.49 & 23.78 & 27.50 \\
\hline DWRB160* & 0.0006 & 0.0266 & 0.0299 & 0.0316 & 0.0267 & 2.57 & 20.62 & 25.28 & 28.88 & 29.55 \\
\hline DWRB184 & 0.1246 & 0.0627 & 0.0426 & 0.0307 & 0.0250 & 36.87 & 36.97 & 37.14 & 38.12 & 38.60 \\
\hline Andreia & 0.0066 & 0.0046 & 0.0134 & 0.0382 & 0.0286 & 8.51 & 9.66 & 16.55 & 28.90 & 29.11 \\
\hline PL904 & 0.0132 & 0.0257 & 0.0289 & 0.0202 & 0.0227 & 12.01 & 21.18 & 25.59 & 26.53 & 27.78 \\
\hline RD2849 (c) & 0.0000 & 0.0018 & 0.0017 & 0.0073 & 0.0229 & 0.15 & 5.38 & 6.13 & 11.82 & 13.52 \\
\hline DWRB101 (c) & 0.0138 & 0.0089 & 0.0072 & 0.0231 & 0.0178 & 12.26 & 13.52 & 14.29 & 22.18 & 22.41 \\
\hline Explorer & 0.0333 & 0.0240 & 0.0165 & 0.0137 & 0.0193 & 19.07 & 21.94 & 22.11 & 23.63 & 24.02 \\
\hline DWRB123 (c) & 0.0046 & 0.0075 & 0.0124 & 0.0176 & 0.0186 & 7.07 & 11.56 & 16.21 & 20.18 & 21.88 \\
\hline RD2985 & 0.0127 & 0.0107 & 0.0112 & 0.0227 & 0.0222 & 11.75 & 14.40 & 16.69 & 23.48 & 24.93 \\
\hline BH902 (c) & 0.0378 & 0.0436 & 0.0293 & 0.0201 & 0.0165 & 20.31 & 28.40 & 28.46 & 29.26 & 29.38 \\
\hline KB1634 & 0.0043 & 0.0098 & 0.0196 & 0.0140 & 0.0216 & 6.89 & 13.01 & 19.98 & 20.93 & 21.59 \\
\hline DWRB187 & 0.0027 & 0.0113 & 0.0365 & 0.0296 & 0.0261 & 5.44 & 13.73 & 26.41 & 28.60 & 29.05 \\
\hline ABI Voyager & 0.0009 & 0.0540 & 0.0362 & 0.0255 & 0.0184 & 3.11 & 29.38 & 29.44 & 30.60 & 30.60 \\
\hline Danielle & 0.0313 & 0.0158 & 0.0105 & 0.0270 & 0.0215 & 18.49 & 18.54 & 18.54 & 26.46 & 26.52 \\
\hline PL905 & 0.0045 & 0.0059 & 0.0062 & 0.0051 & 0.0103 & 7.00 & 10.39 & 12.11 & 13.12 & 13.52 \\
\hline RD2987 & 0.0082 & 0.0089 & 0.0060 & 0.0077 & 0.0186 & 9.45 & 12.89 & 12.92 & 15.00 & 18.97 \\
\hline
\end{tabular}

$\mathrm{EV}=$ Eigenvector, $\mathrm{AMGE}=$ Sum across environments of GEI, SIPC $=$ Sum of the value of the IPC Scores, $\mathrm{D}=$ Parameter of Annicchiarico

(Tables 4 and 5). In recent studies, agronomic concept of stability would be more preferred instead of static concept of stability (Karimizadeh et al., 2016). Using first two IPCAs in stability analysis could benefits dynamic concept of stability in identification of the stable high yielder genotypes.

ASV recommended G12, G10, G22 \& G15 as of stable performance and unsuitable were G9, G2 (Table 3). Considering first two IPCAs in ASV measure used $53.7 \%$ of $\mathrm{G} \times \mathrm{E}$ interaction. The two IPCAs have different values and meanings and the ASV parameter using the Pythagoras theorem and to get estimated values between IPCA1 and IPCA2 scores to produce a balanced measure between the two IPCA scores (Purchase, 1997). Also, ASV parameter of this investigation used advantages of cross validation due to computation from first two IPCAs. Results put forward by ASV measure have many similarities with the other AMMI stability parameters which calculated from the first two IPCAs scores (Carlos \& Krzanowski, 2006).

Minimum values EV3 preferred G12, G23, G22, G13 as well of unstable performance of G2, G5 while SIPC3 pointed towards G6, G19, G14, G20 and G11, G2 whereas D3 for G12, G22, G23, G13 \& G2, G9; ASTAB3 measure considered G12, G22, G23, G13 \& G2, G9 (Table 4). G22, G12, G23, G3 preferred by least values EV5 and maximum values found for G2, G10, measure SIPC5 identified G21, G6, G20, G14 and G11, G2 whereas D5 considered G12, G22, G23, G3 as suitable \& G2, G9 as unsuitable ones; ASTAB5 selected G12, G22, G23, G3 as suitable \& G2, G9 as unsuitable genotypes. 
Table 5 Further AMMI based estimates for GxE interaction analysis

\begin{tabular}{|c|c|c|c|c|c|c|c|c|c|c|}
\hline & SIPC1 & SIPC2 & SIPC3 & SIPC5 & SIPC7 & ASTAB 1 & ASTAB2 & ASTAB3 & ASTAB5 & ASTAB7 \\
\hline DWRB181 & 1.29 & 2.15 & 1.59 & 2.87 & 3.04 & 16.89 & 23.96 & 26.74 & 46.15 & 46.77 \\
\hline RD2986 & 3.00 & 1.54 & 4.12 & 4.34 & 3.02 & 92.22 & 112.48 & 170.76 & 182.36 & 187.98 \\
\hline KB1638 & -1.44 & -1.09 & -0.69 & -0.61 & 1.20 & 21.27 & 22.47 & 23.88 & 33.56 & 44.00 \\
\hline DWRB183 & 1.13 & 3.08 & 3.03 & 3.49 & 3.41 & 12.94 & 49.15 & 49.18 & 51.70 & 57.65 \\
\hline DWRB182 & 1.87 & 1.84 & -1.02 & -0.22 & 0.59 & 35.82 & 35.83 & 107.22 & 110.30 & 127.34 \\
\hline RD2988 & -1.70 & -3.42 & -4.44 & -4.44 & -3.24 & 29.69 & 57.35 & 66.48 & 114.36 & 119.61 \\
\hline DWBR137 & -0.74 & 1.28 & 0.52 & -1.08 & -2.24 & 5.55 & 43.84 & 48.78 & 62.10 & 96.55 \\
\hline DWRB160* & -0.25 & 1.91 & 0.24 & -1.37 & -2.84 & 0.65 & 44.95 & 69.37 & 96.06 & 103.54 \\
\hline DWRB184 & 3.61 & 3.89 & 3.47 & 2.35 & 1.45 & 133.02 & 133.76 & 135.26 & 145.33 & 151.06 \\
\hline Andreia & 0.83 & 0.35 & 1.88 & -1.29 & -1.02 & 7.08 & 9.30 & 29.94 & 101.80 & 104.11 \\
\hline PL904 & 1.18 & 3.02 & 4.66 & 4.79 & 6.91 & 14.11 & 46.33 & 69.92 & 76.32 & 90.93 \\
\hline RD2849 (c) & 0.01 & 0.58 & 0.92 & 2.81 & 1.38 & 0.00 & 3.07 & 4.04 & 17.56 & 46.37 \\
\hline DWRB101 (c) & -1.20 & -1.80 & -1.27 & 1.86 & 1.01 & 14.71 & 18.15 & 20.60 & 59.25 & 61.54 \\
\hline Explorer & -1.87 & -3.01 & -3.33 & -4.12 & -5.98 & 35.58 & 48.03 & 48.88 & 57.82 & 73.24 \\
\hline DWRB123 (c) & -0.69 & -1.66 & -0.36 & 1.31 & 0.10 & 4.90 & 13.75 & 28.50 & 48.28 & 59.51 \\
\hline RD2985 & -1.15 & -2.03 & -1.07 & -0.51 & -1.96 & 13.51 & 20.84 & 28.97 & 64.60 & 75.69 \\
\hline BH902 (c) & -1.99 & 0.11 & 0.33 & 1.39 & 1.01 & 40.35 & 82.04 & 82.47 & 88.41 & 91.91 \\
\hline KB1634 & -0.67 & 0.49 & 2.23 & 3.32 & 5.51 & 4.64 & 17.53 & 43.82 & 48.85 & 67.74 \\
\hline DWRB187 & 0.53 & -0.80 & -3.38 & -1.33 & -1.13 & 2.89 & 19.71 & 77.86 & 93.97 & 102.37 \\
\hline ABI Voyager & 0.30 & -2.79 & -2.99 & -4.28 & -4.03 & 0.95 & 91.28 & 91.64 & 100.59 & 100.83 \\
\hline Danielle & -1.81 & -1.67 & -1.69 & -5.08 & -5.80 & 33.46 & 33.64 & 33.64 & 80.08 & 83.59 \\
\hline PL905 & 0.69 & -0.13 & -0.84 & -1.16 & 0.12 & 4.80 & 11.03 & 15.46 & 18.75 & 29.38 \\
\hline RD2987 & -0.92 & -1.85 & -1.94 & -3.04 & -0.51 & 8.74 & 16.88 & 16.95 & 24.90 & 48.72 \\
\hline
\end{tabular}

SIPC1 $=$ SIPC for first IPCA, SIPC 2 = SIPC for first two IPCAs, $\ldots$ for

According to D7 minimum values G12, G22, G3, and G23 were genotypes of stable yield while G2 and G9 as undesirable; SIPC7 observed G14, G21, G20, G6 as of stable \& G11, G18 of unstable yield (Tables 4 and 5). EV7 pointed towards G22, G1, G5, G4 \& G2, G7. Measure ASTAB7 identified G22, G3, G12, G1 as desirable and G2, G9 for unstable behavior over the studied environments. Composite measure MASV selected G22, G3, G12, G1 as of stable performance and G2, G5 not recommended for cultivation due to unstable yield behavior.

Finally type 1 of AMMI measures (EV1, ASTAB1, D1), considered G12, G8, G19, G20 as desirable genotypes and G9, G2 as of unstable performance; based on the type 2 (EV2, ASTAB2, D2 and ASV) G12, G10, G22, G15 were genotypes of choice and
G9, G2 as unsuitable; as per type 3 (EV3, ASTAB3 and D3), G22, G12, G23, G3 were stable genotypes and G2, G9 of unstable type; according to the type 5 of AMMI parameters (EV5, ASTAB5, SIPC5 and D5), genotypes G22, G12, G23, G3 and G2 \& G9; lastly based on the type 7 (EV7, ASTAB7, MASV and D7), genotypes G22, G3, G12, G6 and G2 \& G9 were detected as the unstable genotypes. Considering all of the AMMI based measures, only genotypes G12, G13, G22 and G3 had the moderate yield performance while G19 was of high yield.

To better understand the relationship among the AMMI based estimates along with yield, principal component analysis (PCA) was performed. The relationship among these estimates is graphically displayed in a plot of PC1 versus PC2. AMMI based measures along with yield could be divided into three major 


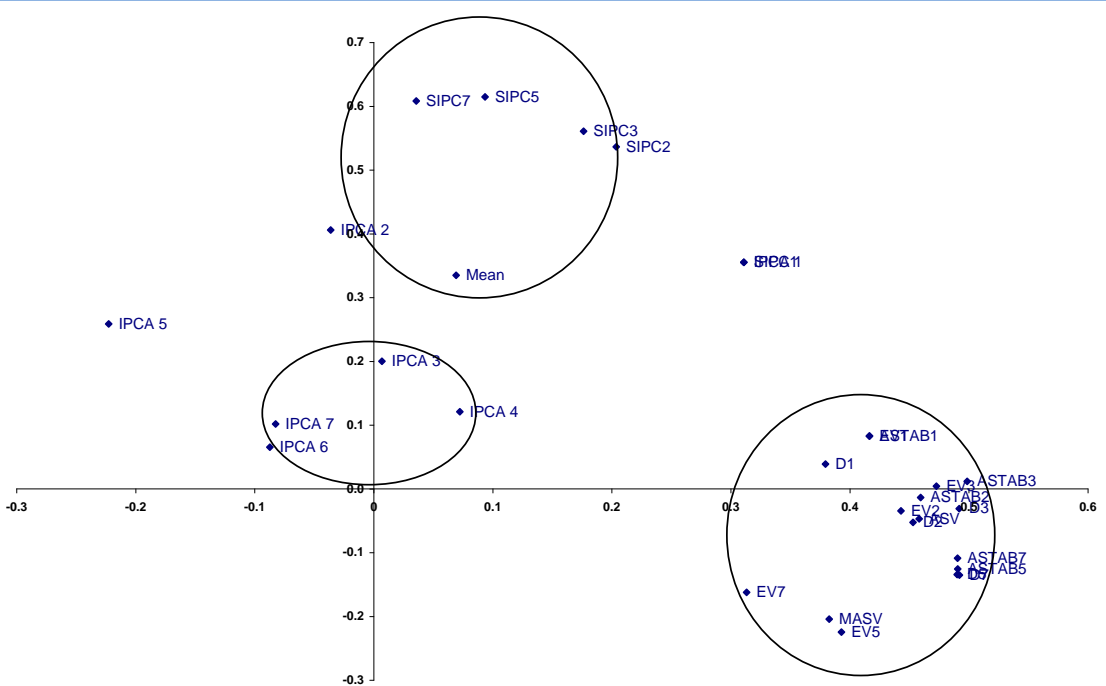

Figure 1 Biplot representation of AMMI based estimates

clusters (Figure 1). Largest group I clubbed 16 measures as ASV, MASV, D1, D2, D3, D5, D7, with EV1, EV2, EV3, EV5, EV7, as well as ASTAB2, ASTAB3 ASTAB1, ASTAB7. Group II contains yield with IPCA2, and SIPC1, SIPC2, SIPC3, SIPC5, SIPC7, whereas IPCA5 was lying far way. Group III contains IPCA3, IPCA4, IPCA6, IPCA7 whereas SIPC1 and IPCA1 were observed as outliers.

Each of the AMMI stability parameters relates to a different concept of yield stability and may be useful to plant breeders attempting to select genotypes with high, stable and predictable yield across environments (Mohammadi et al., 2015). However, it seems that there is no need to consider all of these measures simultaneously, and a few of them should be used in as per maximum usage of $\mathrm{G} \times \mathrm{E}$ interaction sum of squares. AMMI analysis has been observed as useful for exploring complex $\mathrm{G} \times \mathrm{E}$ interaction, improving selections and increasing experimental efficiency (Sabaghnia et al 2013; Bocianowski et al., 2019b).

\section{Conflict of interests}

There is no conflict of interest.

\section{References}

Akbarpour O, Dehghani H, Sorkhi B, Guach G (2014) Evaluation of Genotype $\times$ Environment Interaction in Barley (Hordeum Vulgare L.) Based on AMMI model Using Developed SAS Program. Journal of Agricultural Science \& Technology 16: 919-930.

Annicchiarico P (1997) Joint regression vs AMMI analysis of genotype $\times$ environment interactions for cereals in Italy. Euphytica 94:53-62.
Bocianowski J, Warzecha T, Nowosad K, Bathelt R (2019a) Genotype by environment interaction using AMMI model and estimation of additive and epistasis gene effects for 1000-kernel weight in spring barley (Hordeum vulgare L.) Journal of Applied Genetics 60:127-135

Bocianowski J, Niemann J, Nowosad K (2019b) Genotype-by environment interaction for seed quality traits in inter specific cross-derived Brassica lines using additive main effects and multiplicative interaction model. Euphytica 215:7

Carlos T dos SD, Krzanowski WJ (2006) Choosing Components In The Additive Main Effect and Multiplicative Interaction (AMMI) models. Scientia Agricola (Piracicaba, Braz.), 63:169-175.

Crossa J, Gauch HG, Zobel RW (1990) Additive main effects and multiplicative interaction analysis of two international maize cultivar trials. Crop Science 30: 493-500.

Dehghani H, Sabaghpour SH, Ebadi A (2010) Study of genotype $x$ environment interaction for chickpea yield in Iran. Agronomy Journal 102:1-8.

Flores F, Moreno MT, Cubero JI (1998)A comparison of univariate and multivariate methods to analyze environments. Field Crops Research 56: 271-286

Gauch HG (2007) MATMODEL version 3.0: Open source software for AMMI and related analyses. Crop and Soil Sciences, Cornell University, Ithaca, NY

Karimizadeh R, Ali A, Chinipardaz R, Sofalian O, Ghaffari A (2016) Determining Yield Stability And Model Selection By 
AMMI Method In Rain-Fed Durum Wheat Genotypes. Turkish Journal of Field Crops 21: 174-183

Kendal E, Tekdal S (2016) Application of AMMI Model for Evolution Spring Barley Genotypes in Multi-Environment Trials. Bangladesh Journal of Botany 45: 613-620.

Kilic H (2014) Additive Main Effect and Multiplicative Interactions (AMMI) Analysis of Grain Yield in Barley Genotypes across Environments. Journal of Agricultural Sciences 20: 337-344.

Mohammadi M, Sharifi P, Karimizadeh R, Jafarby JA, Khanzadeh H, Hosseinpour T, Poursiabidi MM, Roustaii M, Hassanpour HM, Mohammadi P (2015) Stability of grain yield of durum wheat genotypes by AMMI model. Agriculture \& Forestry 61: 181-193.

Mortazavian SMM, Nikkhah HR, Hassani FA, Sharif-al-Hosseini M, Taheri M, Mahlooji M (2014) GGE Biplot and AMMI Analysis of Yield Performance of Barley Genotypes across Different Environments in Iran. Journal of Agricultural Science \& Technology 16: 609-622.

Nowosad K, Tratwal A, Bocianowski J (2018) Genotype by environment interaction for grain yield in spring barley using additive main effects and multiplicative interaction model. Cereal Research Communications 46:729-738

Purchase JL (1997) Parametric analysis to describe $G \times E$ interaction and yield stability in winter wheat. Ph.D. thesis submitted to the Department of Agronomy, Faculty of Agriculture, University of the Orange Free State, Bloemfontein, South Africa.
Rao AR, Prabhakaran VT (2005) Use of AMMI in simultaneous selection of genotypes for yield and stability. Journal of the Indian Society of Agricultural Statistics 59:76-82.

Sabaghnia N, Mohammadi M, Karimizadeh R(2012) The Evaluation of Genotype $\times$ Environment Interactions of Durum Wheat's Yield Using of the AMMI Model. Agriculture \& Forestry 55: 5-21.

Sabaghnia N, Mohammadi M, Karimizadeh R (2013) Parameters of AMMI model for yield stability analysis in durum wheat. Agriculturae Conspectus Scientificus 78 : 119-124.

Sneller CH, Kilgore-Norquest L, Dombek D (1997) Repeatability of yield stability statistics in soybean. Crop Science 37: 383-390.

Tekdal S, Kendal E (2018) AMMI Model to Assess Durum Wheat Genotypes in Multi-Environment Trials. Journal of Agricultural Science \& Technology 20: 153-166

Yau SK (1995) Regression and AMMI analysis of genotype $\times$ environment interactions: An empirical comparison. Agronomy Journal 87: 121-126.

Zali H, Farshadfar E, Sabaghpour SH, Karimizadeh R (2012) Evaluation of genotype $x$ environment interaction in chickpea using measures of stability from AMMI model. Annals of Biological Research 3: 3126-3136.

Zobel R (1994) Stress resistance and root systems. In Proceedings of the Workshop on Adaptation of Plants to Serious Stresses. 1-4 August. INTSORMIL Publication 94-2, Institute of Agriculture and Natural Recourses. Lincoln, USA: University of Nebraska. 